\title{
Atomic Shell Structure and Electron Numbers
}

\section{KOHOUT*}

Institut für Theoretische Chemie, Universität Stuttgart, Pfaffenwaldring 55, 70569 Stuttgart, Germany; e-mail: cfam 1019@servus.uni-stuttgart.de

\author{
A. SAVIN \\ Laboratoire Dyamique des Interaction Moléculaires, Universite Pierre et Marie Curie, Place Jussieu, \\ F-75252 Paris Cedex 05, France
}

\begin{abstract}
The electron localization function (ELF) was calculated for the atoms $\mathrm{Li}$ to $\mathrm{Sr}$. The ELF maxima reveal the atomic shell structure for all these atoms. The shells are separated from each other by ELF minima. The integration of the electron density in a shell gives electron numbers. For the valence shell those are in good agreement with the ones expected from the Periodic Table of Elements. (c) 1996 John Wiley \& Sons, Inc.
\end{abstract}

\section{Introduction}

$\mathbf{E}$ very chemist is familiar with the concept of atomic shells. The division into the valence and core shells is widely used in chemistry. Each atomic shell is built up from orbitals with the same principal quantum number. The shells are filled with electrons, according to the Aufbau principle. However, the ambition to make the shell structure of atoms visible by means of some property related to the electron density distribution was followed for many years, with different success. The electron density alone cannot achieve this goal [1]. The monotonically exponential decay yields no information concerning the atomic shells. But other properties derived from the electron density such

\footnotetext{
${ }^{*}$ To whom correspondence should be addressed.
}

as the radial distribution $4 \pi r^{2} \rho[1-4]$, the Laplacian of the electron density $-\nabla^{2} \rho[5,6,13,14]$, the local kinetic energy $E_{\text {kin }}$ of Hunter $[7,8]$, the logarithm of the electron density $[9,10]$, the quantity $-|\nabla \rho| / \rho[11]$, or the average local electrostatic potential function $V(r) / \rho(r)$ [12] are able to resolve, at least partially, the atomic shell structure.

The electron localization function (ELF) first formulated by Becke and Edgecombe [15] is able to visualize the shell structure of atoms, as shown by these authors. They took, as an example for the atomic shells, the noble gases and the $\mathrm{Zn}$ atom. Each atomic shell was indicated by a peak in the ELF vs. radius diagram.

The original formula of Becke and Edgecombe was written as

$$
\mathrm{ELF}=\frac{1}{1+\chi^{2}}
$$


with

$$
\chi=\frac{\sum_{i}^{\sigma}\left|\nabla \psi_{i}\right|^{2}-\frac{1}{4} \frac{\left(\nabla \rho_{\sigma}\right)^{2}}{\rho_{\sigma}}}{2^{5 / 3} \mathcal{c}_{F} \rho_{\sigma}^{5 / 3}}
$$

and

$$
\rho_{\sigma}=\sum_{i}^{\sigma}\left|\psi_{i}\right|^{2},
$$

where the sums include only orbitals occupied with $\sigma$-spin electrons and $\rho_{\sigma}$ is the $\sigma$-spin density; $c_{F}=\frac{3}{10}\left(3 \pi^{2}\right)^{2 / 3}$ is the Fermi constant. This ELF formula is based on the same-spin pair probabilities. A new interpretation of the ELF formula was given by Savin et al. [16]. For closed-shell systems the total electron density $\rho$ (i.e., the sums run over all occupied orbitals) is twice the spin density and

$$
\sum_{i}^{\sigma}\left|\nabla \psi_{i}\right|^{2}=\frac{1}{2} \sum_{j}^{n}\left|\nabla \psi_{j}\right|^{2},
$$

where $n$ is the number of all occupied orbitals. Using this in the ELF formula, the ELF values for the closed-shell system remain unchanged. But the numerator

$$
\tau-\frac{1}{8} \frac{(\nabla \rho)^{2}}{\rho}
$$

with the kinetic energy density

$$
\tau=\frac{1}{2} \sum_{i}^{n}\left|\nabla \psi_{i}\right|^{2}
$$

is now equal to the Pauli kinetic energy density $t_{p}$. The Pauli kinetic energy is the energy required for the redistribution of the electrons according to the Pauli principle.

The kinetic energy density $\tau$ as well as the total density $\rho$ is now computed from all occupied orbitals. Both $\rho$ and $\tau$ are invariant to any unitary transformation of these occupied orbitals. The ELF formula for the closed-shell systems can be written as

$$
\mathrm{ELF}=\left[1+\left(\frac{\tau-\frac{1}{8} \frac{(\nabla \rho)^{2}}{\rho}}{c_{F} \rho^{5 / 3}}\right]^{2}\right]^{-1}
$$

One could well use this formula for open-shell systems too. But in analogy to the spin-density functional theory (see, e.g., Parr and Yang [17]), the Pauli kinetic energy $t_{p}$ can be split into the spin-dependent parts $t_{P, \sigma}$ :

$$
t_{P, \sigma}=\tau_{\sigma}-\frac{1}{8} \frac{\left(\nabla \rho_{\sigma}\right)^{2}}{\rho_{\sigma}},
$$

where $\tau_{\sigma}$ and $\rho_{\sigma}$ are computed from the occupied $\sigma$-spin orbitals only. It is consistent with this approach to use also the kinetic energy density of a spin-polarized homogeneous electron gas as the reference. With this we extend the ELF formula for the spin-polarized systems. For all systems we use the formula

$$
\begin{aligned}
\operatorname{ELF} & =\left[1+\left(\frac{t_{P, \alpha}+t_{P, \beta}}{t_{h, \alpha}+t_{h, \beta}}\right)^{2}\right]^{-1} \\
& =\left[1+\left(\frac{\tau-\frac{1}{8} \frac{\left(\nabla \rho_{\alpha}\right)^{2}}{\rho_{\alpha}}-\frac{1}{8} \frac{\left(\nabla \rho_{\beta}\right)^{2}}{\rho_{\beta}}}{2^{2 / 3} c_{F}\left(\rho_{\alpha}^{5 / 3}+\rho_{\beta}^{5 / 3}\right)}\right]^{2},\right.
\end{aligned}
$$

where $\rho_{\alpha}$ and $\rho_{\beta}$ denote the spin densities; $t_{h, \alpha}$ and $t_{h, \beta}$ are the spin-dependent parts of the kinetic energy density of the spin-polarized homogeneous electron gas. The ELF formula (9) is connected to the kinetic energy required for the distribution of all the electrons (regardless of the spin) according to the Pauli principle. The ELF values are bound between 0 (low localization) and 1 (high localization).

Of course, one could also consider two separate pictures for each spin using the original formula (1) or formula (9). In the present study we have analyzed also these spin-dependent ELF data.

\section{Results and Discussion}

As shown by Becke and Edgecombe [15] ELF was able to visualize the complete shell structure of the noble gases and the $\mathrm{Zn}$ atom. In this study we wish to examine this for all the atoms $\mathrm{Li}$ to $\mathrm{Sr}$. ELF was generated using the basis sets of Clementi and Roetti [18] for the Hatree-Fock calculations of 
the neutral atoms. For all the tested atoms an ELF maximum was found for each atomic shell. Close to the nucleus the $K$ shell has an ELF value of approximately 1 . The successive ELF maxima mark the atomic shells. There are two possibilities for the ELF shape of the valence (last) shell. If the atom has only s electrons in the valence shell, then the localization for the valence shell grows fast to a high value (almost 1.0) and reaches the maximal localization at infinity, as shown in Figure 1 for potassium. Figure 2 demonstrates the other case, when more electrons are present in the valence shell. Then, after ELF attains its maximal value for the valence shell, the localization decays to zero at large distances from the nucleus. The explanation for this behavior can be found in Ref. [15].

ELF fulfilled the goal to resolve the atomic shell structure for the atoms $\mathrm{Li}$ to Sr. According to the Periodic Table of the Elements each atomic shell should be occupied by specified number of electrons. Let us suppose that the atomic shells indicated by the ELF maxima are separated by the ELF minima. Then the ELF minimum between a particular and the successor shell can be designated as the radius of the particular shell. The valence shell, of course, has for an atomic calculation a boundary only to the penultimate shell and extends to infinity. In the Table I are given the number electrons in each shell as well as the shell radius. The number of electrons in a shell was computed by the numerical integration of the electron density between the boundaries of the shell. In the case of the valence shell the outer boundary was set to the distance of 10 a.u. from the nucleus. This distance

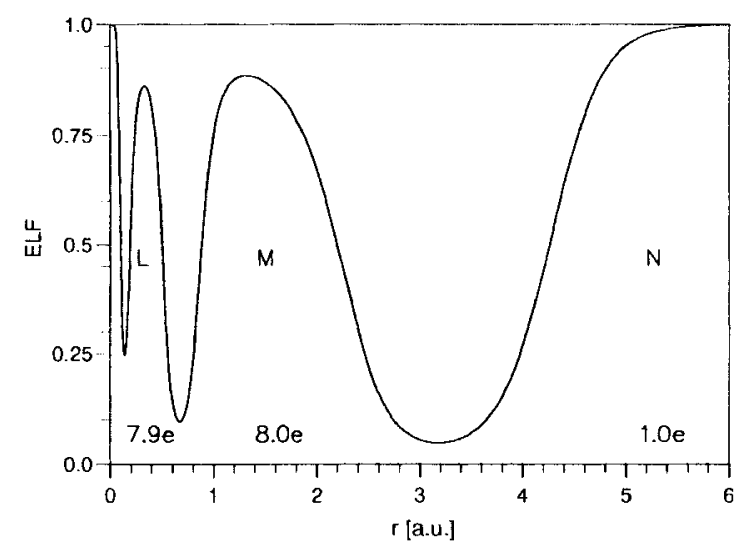

FIGURE 1. The shell structure of the potassium atom. The shells are denoted by capital letters and the number of electrons are given at the bottom of the peaks.

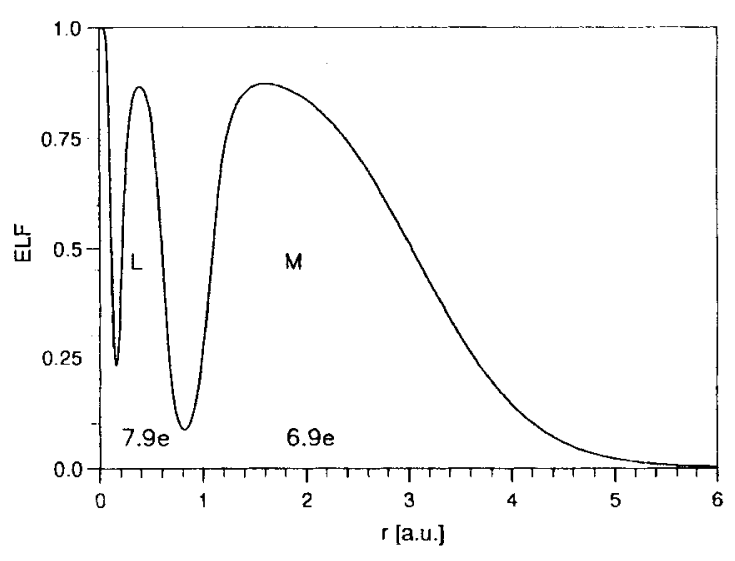

FIGURE 2. The shell structure of the chlorine atom. The shells are denoted by capital letters and the number of electrons are given at the bottom of the peaks.

is large enough as shown by an integration of the electron density in a sphere of the same radius. The total number of electrons found in the sphere is equal to the nuclear charge in all cases (last column of Table I).

For the atoms $C$ to Ar a charge of typically 0.1 electron is missing in the $\mathrm{L}$ shell as well as the $\mathrm{M}$ shell of $\mathrm{Na}$ to Ar. This charge is found in the $\mathrm{K}$ shell of these atoms. So the radius of the first shell seems to be little to large compared to the "ideal" shells of Schmider et al. [19] (an ideal shell is per definition occupied by the number of electrons in accordance with the Periodic Table of the Elements). The same is true for potassium and calcium if we consider the depletion of the $\mathrm{N}$ shell. Starting with the atom Sc, there is an excessive charge of 0.1 to 0.2 electron also in the valence $\mathrm{N}$ shell (in the case of $\mathrm{Cr}$ even 0.4 electron). From $\mathrm{Mn}$ on more electrons than expected are found in the $\mathrm{L}$ shell, with an error up to 0.8 electron. In contrast to that, the $\mathrm{M}$ shell if occupied by the $d$ electrons gives low electron numbers, with the largest deviations of 0.8 to 0.9 electron for the atoms $\mathrm{Cu}$ to $\mathrm{Sr}$.

The examination of the orbital contributions to the $\mathrm{M}$ shell density of $\mathrm{Zn}$ atom have shown that only 16.2 electrons are originating from the orbitals with the principal quantum number 3 . The remaining charge of one electron (giving the 17.2 electrons found) is coming from the surrounding shells. We have computed also the $\mathrm{Cd}$ atom which has $d$ electrons in the $\mathrm{M}$ as well as the $\mathrm{N}$ shell. Again we have found only 17.1 electrons in the $M$ shell (extending over the region 0.183 to 0.577 a.u. from the nucleus). The orbital contribution analysis of 
TABLE I

The ELF shell radii and electron numbers computed from the atomic data of Clementi and Roetti [18] using the ELF formula (9). ${ }^{a}$

\begin{tabular}{|c|c|c|c|c|c|c|c|c|c|c|}
\hline Atom & $\begin{array}{l}q^{K} \\
(e)\end{array}$ & $\begin{array}{c}r^{k} \\
\text { (a.u.) }\end{array}$ & $\begin{array}{l}q^{L} \\
(e)\end{array}$ & $\begin{array}{c}r^{L} \\
\text { (a.u.) }\end{array}$ & $\begin{array}{l}q^{M} \\
(e)\end{array}$ & $\begin{array}{c}r^{M} \\
\text { (a.u.) }\end{array}$ & $\begin{array}{l}q^{N} \\
(e)\end{array}$ & $\begin{array}{c}r^{N} \\
\text { (a.u.) }\end{array}$ & $\begin{array}{l}q^{\circ} \\
(e)\end{array}$ & $\begin{array}{c}Q_{0}^{10} \\
(e)\end{array}$ \\
\hline${ }^{3} \mathrm{Li}\left({ }^{2} \mathrm{~S}\right)$ & 2.0 & 1.53 & 1.0 & - & - & - & - & - & - & 3.0 \\
\hline${ }^{4} \mathrm{Be}\left({ }^{1} \mathrm{~S}\right)$ & 2.0 & 1.02 & 2.0 & - & -- & - & - & - & - & 4.0 \\
\hline${ }^{5} B\left({ }^{2} P\right)$ & 2.0 & 0.75 & 3.0 & - & - & - & - & - & - & 5.0 \\
\hline${ }^{6} \mathrm{C}\left({ }^{3} \mathrm{P}\right)$ & 2.1 & 0.58 & 3.9 & - & - & - & - & - & - & 6.0 \\
\hline${ }^{7} N\left({ }^{4} S\right)$ & 2.1 & 0.47 & 4.9 & - & - & - & - & - & - & 7.0 \\
\hline${ }^{8} \mathrm{O}\left({ }^{3} P\right)$ & 2.1 & 0.40 & 5.9 & - & - & - & - & - & - & 8.0 \\
\hline${ }^{9} F\left({ }^{2} P\right)$ & 2.1 & 0.34 & 6.9 & - & - & - & - & - & - & 9.0 \\
\hline${ }^{10} \mathrm{Ne}\left({ }^{1} \mathrm{~S}\right)$ & 2.2 & 0.30 & 7.8 & - & - & - & - & - & - & 10.0 \\
\hline${ }^{11} \mathrm{Na}\left({ }^{2} \mathrm{~S}\right)$ & 2.2 & 0.2640 & 7.9 & 2.135 & 1.0 & - & - & - & - & 11.0 \\
\hline${ }^{12} \mathrm{Mg}\left({ }^{1} \mathrm{~S}\right)$ & 2.2 & 0.2364 & 7.9 & 1.686 & 2.0 & - & - & - & - & 12.0 \\
\hline${ }^{13} \mathrm{Al}\left({ }^{2} \mathrm{P}\right)$ & 2.2 & 0.2138 & 7.9 & 1.395 & 2.9 & - & - & - & - & 13.0 \\
\hline${ }^{14} \mathrm{Si}\left({ }^{3} \mathrm{P}\right)$ & 2.2 & 0.1951 & 7.9 & 1.183 & 3.9 & - & - & - & - & 14.0 \\
\hline${ }^{15} \mathrm{P}\left({ }^{4} \mathrm{~S}\right)$ & 2.2 & 0.1793 & 7.9 & 1.024 & 5.0 & - & - & - & - & 15.0 \\
\hline${ }^{16} \mathrm{~S}\left({ }^{3} \mathrm{P}\right)$ & 2.2 & 0.1684 & 7.9 & 0.912 & 5.9 & - & - & - & - & 16.0 \\
\hline${ }^{17} \mathrm{Cl}\left({ }^{2} \mathrm{P}\right)$ & 2.2 & 0.1542 & 7.9 & 0.817 & 6.9 & - & - & - & - & 17.0 \\
\hline${ }^{18} \operatorname{Ar}\left({ }^{1} \mathrm{~S}\right)$ & 2.2 & 0.1439 & 7.9 & 0.739 & 7.9 & - & - & - & - & 18.0 \\
\hline${ }^{19} K\left({ }^{2} S\right)$ & 2.2 & 0.1350 & 7.9 & 0.672 & 8.0 & 3.07 & 1.0 & - & - & 19.0 \\
\hline${ }^{20} \mathrm{Ca}\left({ }^{1} \mathrm{~S}\right)$ & 2.2 & 0.1270 & 7.9 & 0.618 & 8.0 & 2.55 & 1.9 & - & - & 20.0 \\
\hline${ }^{21} \mathrm{Sc}\left({ }^{2} \mathrm{D}\right)$ & 2.2 & 0.1200 & 7.9 & 0.573 & 8.8 & 2.39 & 2.1 & - & - & 21.0 \\
\hline${ }^{22} \mathrm{Ti}\left({ }^{3} \mathrm{~F}\right)$ & 2.2 & 0.1138 & 7.9 & 0.535 & 9.7 & 2.29 & 2.1 & - & - & 22.0 \\
\hline${ }^{23} V\left({ }^{4} F\right)$ & 2.2 & 0.1082 & 8.0 & 0.501 & 10.7 & 2.20 & 2.2 & - & - & 23.0 \\
\hline${ }^{24} \mathrm{Cr}\left({ }^{7} \mathrm{~S}\right)$ & 2.2 & 0.1032 & 8.0 & 0.472 & 12.3 & 2.37 & 1.4 & - & - & 24.0 \\
\hline${ }^{25} \mathrm{Mn}\left({ }^{6} \mathrm{~S}\right)$ & 2.2 & 0.0986 & 8.1 & 0.444 & 12.6 & 2.07 & 2.2 & - & - & 25.0 \\
\hline${ }^{26} \mathrm{Fe}\left({ }^{5} \mathrm{D}\right)$ & 2.2 & 0.0944 & 8.1 & 0.420 & 13.5 & 2.01 & 2.2 & - & - & 26.0 \\
\hline${ }^{27} \mathrm{Co}\left({ }^{4} \mathrm{~F}\right)$ & 2.2 & 0.0903 & 8.2 & 0.399 & 14.4 & 1.95 & 2.2 & - & - & 27.0 \\
\hline${ }^{28} \mathrm{Ni}\left({ }^{3} \mathrm{~F}\right)$ & 2.2 & 0.0870 & 8.3 & 0.379 & 15.3 & 1.89 & 2.2 & - & - & 28.0 \\
\hline${ }^{29} \mathrm{Cu}\left({ }^{2} \mathrm{~S}\right)$ & 2.2 & 0.0837 & 8.3 & 0.362 & 17.2 & 2.17 & 1.3 & - & - & 29.0 \\
\hline${ }^{30} \mathrm{Zn}\left({ }^{1} \mathrm{~S}\right)$ & 2.2 & 0.0807 & 8.4 & 0.345 & 17.2 & 1.81 & 2.2 & - & - & 30.0 \\
\hline${ }^{31} \mathrm{Ga}\left({ }^{2} \mathrm{P}\right)$ & 2.2 & 0.0778 & 8.4 & 0.329 & 17.2 & 1.59 & 3.2 & - & - & 31.0 \\
\hline${ }^{32} \mathrm{Ge}\left({ }^{3} \mathrm{P}\right)$ & 2.2 & 0.0751 & 8.4 & 0.315 & 17.2 & 1.42 & 4.2 & - & - & 32.0 \\
\hline${ }^{33}$ As $\left({ }^{4} S\right)$ & 2.2 & 0.0726 & 8.4 & 0.301 & 17.2 & 1.28 & 5.2 & - & - & 33.0 \\
\hline${ }^{34} \mathrm{Se}\left({ }^{3} \mathrm{P}\right)$ & 2.2 & 0.0702 & 8.5 & 0.289 & 17.2 & 1.18 & 6.1 & - & - & 34.0 \\
\hline${ }^{35} \mathrm{Br}\left({ }^{2} \mathrm{P}\right)$ & 2.2 & 0.0680 & 8.5 & 0.278 & 17.2 & 1.10 & 7.1 & - & - & 35.0 \\
\hline${ }^{36} \mathrm{Kr}\left({ }^{1} \mathrm{~S}\right)$ & 2.2 & 0.0659 & 8.5 & 0.267 & 17.1 & 1.02 & 8.1 & - & - & 36.0 \\
\hline${ }^{37} \mathrm{Rb}\left({ }^{2} \mathrm{~S}\right)$ & 2.2 & 0.0639 & 8.6 & 0.257 & 17.1 & 0.95 & 8.2 & 3.51 & 1.0 & 37.0 \\
\hline${ }^{38} \mathrm{Sr}\left({ }^{1} \mathrm{~S}\right)$ & 2.2 & 0.0621 & 8.6 & 0.248 & 17.1 & 0.89 & 8.3 & 2.95 & 1.9 & 38.0 \\
\hline${ }^{48} \mathrm{Cd}\left({ }^{1} \mathrm{~S}\right)$ & 2.2 & 0.0481 & 8.8 & 0.183 & 17.1 & 0.58 & 17.9 & 2.34 & 2.0 & 48.0 \\
\hline
\end{tabular}

${ }^{a} q^{K}$, electronic charge in the $K$ shell; $r^{K}$, radius of the $K$ shell; and $Q_{0}^{10}$, total electronic charge in sphere of 10 a.u. radius.

the $\mathrm{M}$ shell gives 14.9 electrons coming from the third subshell ( $3 s, 3 p$, and $3 d$ orbitals). The $\mathrm{N}$ shell ( 0.577 to 2.34 a.u. from the nucleus) is occupied by 17.9 electrons (and exactly 2 electrons were found in the valence shell). This is very close to the expected 18 electrons, although the fourth subshell $(4 s, 4 p$, and $4 d$ orbitals) is contributing with only 16.2 electrons (the same value as for the third subshell contribution to the $\mathrm{M}$ shell of the $\mathrm{Zn}$ atom, see above).
In the introduction we mentioned that one could also use the ELF formula (7) for all systems. The results for the shell radii and the shell electron numbers using this ELF formula are given in Table II. For the closed-shell systems the data remains unchanged as expected. The largest differences in the shell radii as compared to the calculations with the spin-polarized ELF formula (9) are found for the valence shell of the alkali metals. The electron numbers for a given shell are either of the same 
TABLE II

The ELF shell radii and electron numbers computed from the atomic data of Clementi and Roetti [18] using the ELF Formula 7. ${ }^{\mathrm{a}}$

\begin{tabular}{|c|c|c|c|c|c|c|c|c|c|c|}
\hline Atom & $\begin{array}{l}q^{K} \\
(e)\end{array}$ & $\begin{array}{c}r^{k} \\
\text { (a.u.) }\end{array}$ & $\begin{array}{l}q^{L} \\
(e)\end{array}$ & $\begin{array}{c}r^{L} \\
\text { (a.u.) }\end{array}$ & $\begin{array}{l}q^{M} \\
(e)\end{array}$ & $\begin{array}{l}r^{M} \\
\text { (a.u.) }\end{array}$ & $\begin{array}{l}q^{N} \\
(e)\end{array}$ & $\begin{array}{c}r^{N} \\
\text { (a.u.) }\end{array}$ & $\begin{array}{l}q^{O} \\
(e)\end{array}$ & $\begin{array}{l}Q_{0}^{10} \\
(e)\end{array}$ \\
\hline${ }^{3} \mathrm{Li}\left({ }^{2} \mathrm{~S}\right)$ & 2.0 & 1.62 & 1.0 & - & - & - & - & - & - & 3.0 \\
\hline${ }^{4} \mathrm{Be}\left({ }^{1} \mathrm{~s}\right)$ & 2.0 & 1.02 & 2.0 & - & - & - & - & - & - & 4.0 \\
\hline${ }^{5} B\left({ }^{2} P\right)$ & 2.0 & 0.75 & 3.0 & - & - & 一 & - & - & - & 5.0 \\
\hline${ }^{6} \mathrm{C}\left({ }^{3} \mathrm{P}\right)$ & 2.1 & 0.58 & 3.9 & - & - & - & - & - & - & 6.0 \\
\hline${ }^{7} N\left({ }^{4} S\right)$ & 2.1 & 0.48 & 4.9 & - & - & - & - & - & - & 7.0 \\
\hline${ }^{8} O\left({ }^{3} \mathrm{P}\right)$ & 2.1 & 0.40 & 5.9 & - & - & - & - & - & - & 8.0 \\
\hline${ }^{9} \mathrm{~F}\left({ }^{2} \mathrm{P}\right)$ & 2.1 & 0.34 & 6.9 & - & - & - & - & - & - & 9.0 \\
\hline${ }^{10} \mathrm{Ne}\left({ }^{1} \mathrm{~S}\right)$ & 2.2 & 0.30 & 7.8 & - & - & - & - & - & - & 10.0 \\
\hline${ }^{11} \mathrm{Na}\left({ }^{2} \mathrm{~S}\right)$ & 2.2 & 0.2641 & 7.9 & 2.263 & 1.0 & - & - & - & - & 11.0 \\
\hline${ }^{12} \mathrm{Mg}\left({ }^{1} \mathrm{~s}\right)$ & 2.2 & 0.2363 & 7.9 & 1.686 & 2.0 & - & - & - & - & 12.0 \\
\hline${ }^{13} \mathrm{Al}\left({ }^{2} \mathrm{P}\right)$ & 2.2 & 0.2138 & 7.9 & 1.397 & 2.9 & - & - & - & - & 13.0 \\
\hline${ }^{14} \mathrm{Si}\left({ }^{3} \mathrm{P}\right)$ & 2.2 & 0.1951 & 7.9 & 1.189 & 3.9 & - & - & - & - & 14.0 \\
\hline${ }^{15} \mathrm{P}\left({ }^{4} \mathrm{~S}\right)$ & 2.2 & 0.1793 & 7.9 & 1.034 & 4.9 & - & - & - & - & 15.0 \\
\hline${ }^{16} \mathrm{~S}\left({ }^{3} \mathrm{P}\right)$ & 2.2 & 0.1683 & 7.9 & 0.914 & 5.9 & - & - & - & - & 16.0 \\
\hline${ }^{17} \mathrm{Cl}\left({ }^{2} \mathrm{P}\right)$ & 2.2 & 0.1541 & 7.9 & 0.817 & 6.9 & - & - & - & - & 17.0 \\
\hline${ }^{18} \operatorname{Ar}\left({ }^{+} \mathrm{S}\right)$ & 2.2 & 0.1439 & 7.9 & 0.739 & 7.9 & - & - & - & - & 18.0 \\
\hline${ }^{19} \mathrm{~K}\left({ }^{2} \mathrm{~S}\right)$ & 2.2 & 0.1350 & 7.9 & 0.673 & 8.0 & 3.27 & 0.9 & - & - & 19.0 \\
\hline${ }^{20} \mathrm{Ca}\left({ }^{1} \mathrm{~S}\right)$ & 2.2 & 0.1270 & 7.9 & 0.618 & 8.0 & 2.55 & 1.9 & - & - & 20.0 \\
\hline${ }^{21} S c\left({ }^{2} D\right)$ & 2.2 & 0.1200 & 7.9 & 0.573 & 8.8 & 2.39 & 2.1 & - & - & 21.0 \\
\hline${ }^{22} \mathrm{Ti}\left({ }^{3} \mathrm{~F}\right)$ & 2.2 & 0.1138 & 7.9 & 0.535 & 9.7 & 2.29 & 2.1 & - & - & 22.0 \\
\hline${ }^{23} \mathrm{~V}\left({ }^{4} \mathrm{~F}\right)$ & 2.2 & 0.1082 & 8.0 & 0.501 & 10.7 & 2.20 & 2.2 & - & - & 23.0 \\
\hline${ }^{24} \mathrm{Cr}\left({ }^{7} \mathrm{~S}\right)$ & 2.2 & 0.1032 & 8.0 & 0.472 & 12.5 & 2.47 & 1.3 & - & - & 24.0 \\
\hline${ }^{25} \mathrm{Mn}\left({ }^{6} \mathrm{~S}\right)$ & 2.2 & 0.0986 & 8.1 & 0.445 & 12.5 & 2.07 & 2.2 & - & - & 25.0 \\
\hline${ }^{26} \mathrm{Fe}\left({ }^{5} \mathrm{D}\right)$ & 2.2 & 0.0944 & 8.1 & 0.421 & 13.4 & 2.00 & 2.2 & - & - & 26.0 \\
\hline${ }^{27} \mathrm{Co}\left({ }^{4} \mathrm{~F}\right)$ & 2.2 & 0.0903 & 8.2 & 0.399 & 14.3 & 1.94 & 2.2 & - & - & 27.0 \\
\hline${ }^{28} \mathrm{Ni}\left({ }^{3} \mathrm{~F}\right)$ & 2.2 & 0.0870 & 8.2 & 0.379 & 15.3 & 1.89 & 2.2 & - & - & 28.0 \\
\hline${ }^{29} \mathrm{Cu}\left({ }^{2} \mathrm{~S}\right)$ & 2.2 & 0.0837 & 8.3 & 0.362 & 17.4 & 2.40 & 1.1 & - & - & 29.0 \\
\hline${ }^{30} \mathrm{Zn}\left({ }^{1} \mathrm{~S}\right)$ & 2.2 & 0.0807 & 8.4 & 0.345 & 17.2 & 1.81 & 2.2 & - & - & 30.0 \\
\hline${ }^{31} \mathrm{Ga}\left({ }^{2} \mathrm{P}\right)$ & 2.2 & 0.0778 & 8.4 & 0.329 & 17.2 & 1.60 & 3.1 & - & - & 31.0 \\
\hline${ }^{32} \mathrm{Ge}\left({ }^{3} \mathrm{P}\right)$ & 2.2 & 0.0751 & 8.4 & 0.315 & 17.2 & 1.43 & 4.1 & - & - & 32.0 \\
\hline${ }^{33} \mathrm{As}\left({ }^{4} \mathrm{~S}\right)$ & 2.2 & 0.0726 & 8.5 & 0.301 & 17.2 & 1.30 & 5.1 & - & - & 33.0 \\
\hline${ }^{34} \mathrm{Se}\left({ }^{3} \mathrm{P}\right)$ & 2.2 & 0.0702 & 8.5 & 0.289 & 17.2 & 1.19 & 6.1 & - & - & 34.0 \\
\hline${ }^{35} \mathrm{Br}\left({ }^{2} \mathrm{P}\right)$ & 2.2 & 0.0680 & 8.5 & 0.278 & 17.1 & 1.10 & 7.1 & - & - & 35.0 \\
\hline${ }^{36} \mathrm{Kr}\left({ }^{1} \mathrm{~S}\right)$ & 2.2 & 0.0659 & 8.5 & 0.267 & 17.1 & 1.02 & 8.1 & - & - & 36.0 \\
\hline${ }^{37} \mathrm{Rb}\left({ }^{2} \mathrm{~S}\right)$ & 2.2 & 0.0639 & 8.6 & 0.257 & 17.1 & 0.95 & 8.2 & 3.72 & 0.9 & 37.0 \\
\hline${ }^{38} \mathrm{Sr}\left({ }^{1} \mathrm{~S}\right)$ & 2.2 & 0.0621 & 8.6 & 0.248 & 17.0 & 0.89 & 8.3 & 2.95 & 1.9 & 38.0 \\
\hline${ }^{48} \mathrm{Cd}\left({ }^{1} \mathrm{~s}\right)$ & 2.2 & 0.0481 & 8.8 & 0.183 & 17.1 & 0.58 & 17.9 & 2.34 & 2.0 & 48.0 \\
\hline
\end{tabular}

${ }^{a} q^{K}$, electronic charge in the $K$ shell; $r^{K}$, radius of the $K$ shell; and $Q_{0}^{10}$, total electronic charge in sphere of 10 a.u. radius.

magnitude (inner shells) or up to 0.1 electron smaller in the case of the ELF formula (7) (valence shell).

We have also computed ELF for each spin separately. In Tables III and IV are given the shell radii and electron numbers determined from these ELF data. Of course, for the closed-shell systems the shell radii must be identical in all three tables. For the spin-polarized systems the radii of the inner shells computed from the spin densities are also close to the ones for the total density. Larger differences between the spin-up and spin-down shell radii are found in the outer shells, thereby being largest for the high-spin systems (compare the L-shell radii for the phosphorus or chromium atom). The number of spin-up and spin-down electrons, respectively, found in the shells are again close to the ideal ones. It is interesting that for each shell the difference to the ideal occupation as examined above for the total density is now split 
TABLE III

The ELF shell radii and electron numbers for the up spin computed from the atomic data of Clementi and Roetti [18]. ${ }^{a}$

\begin{tabular}{|c|c|c|c|c|c|c|c|c|c|c|}
\hline Atom & $\begin{array}{l}q^{K} \\
(e)\end{array}$ & $\begin{array}{c}r^{k} \\
\text { (a.u.) }\end{array}$ & $\begin{array}{l}q^{L} \\
(e)\end{array}$ & $\begin{array}{c}r^{L} \\
\text { (a.u.) }\end{array}$ & $\begin{array}{l}q^{M} \\
(e)\end{array}$ & $\begin{array}{c}r^{M} \\
\text { (a.u.) }\end{array}$ & $\begin{array}{l}q^{N} \\
(e)\end{array}$ & $\begin{array}{c}r^{N} \\
(\text { a.u. })\end{array}$ & $\begin{array}{l}q^{\circ} \\
(e)\end{array}$ & $\begin{array}{c}Q_{0}^{10} \\
\text { (a.u.) }\end{array}$ \\
\hline${ }^{3} \mathrm{Li}\left({ }^{2} \mathrm{~S}\right)$ & 1.0 & 1.48 & 1.0 & - & - & - & - & - & - & 2.0 \\
\hline${ }^{4} \mathrm{Be}\left({ }^{1} \mathrm{~S}\right)$ & 1.0 & 1.02 & 1.0 & - & - & - & - & - & - & 2.0 \\
\hline${ }^{5} B\left({ }^{2} P\right)$ & 1.0 & 0.73 & 2.0 & - & - & - & - & - & - & 3.0 \\
\hline${ }^{6} \mathrm{C}\left({ }^{3} \mathrm{P}\right)$ & 1.1 & 0.55 & 2.9 & - & -- & - & - & - & - & 4.0 \\
\hline${ }^{7} \mathrm{~N}\left({ }^{4} \mathrm{~S}\right)$ & 1.1 & 0.44 & 3.9 & - & - & - & - & - & - & 5.0 \\
\hline${ }^{8} \mathrm{O}\left({ }^{3} \mathrm{P}\right)$ & 1.1 & 0.38 & 3.9 & - & - & - & - & - & - & 5.0 \\
\hline${ }^{9} F\left({ }^{2} P\right)$ & 1.1 & 0.34 & 3.9 & - & - & - & $\ldots$ & - & - & 5.0 \\
\hline${ }^{10} \mathrm{Ne}\left({ }^{1} \mathrm{~S}\right)$ & 1.1 & 0.30 & 3.9 & - & - & - & - & - & - & 5.0 \\
\hline${ }^{11} \mathrm{Na}\left({ }^{2} \mathrm{~S}\right)$ & 1.1 & 0.2640 & 3.9 & 2.070 & 1.0 & - & - & - & - & 6.0 \\
\hline${ }^{12} \mathrm{Mg}\left({ }^{1} \mathrm{~S}\right)$ & 1.1 & 0.2364 & 3.9 & 1.686 & 1.0 & - & - & - & - & 6.0 \\
\hline${ }^{13} \mathrm{Al}\left({ }^{2} \mathrm{P}\right)$ & 1.1 & 0.2137 & 3.9 & 1.372 & 2.0 & 一 & - & - & - & 7.0 \\
\hline${ }^{14} \mathrm{Si}\left({ }^{3} \mathrm{P}\right)$ & 1.1 & 0.1947 & 3.9 & 1.149 & 3.0 & - & - & - & - & 8.0 \\
\hline${ }^{15} P\left({ }^{4} S\right)$ & 1.1 & 0.1787 & 3.9 & 0.986 & 4.0 & - & - & - & - & 9.0 \\
\hline${ }^{16} \mathrm{~S}\left({ }^{3} \mathrm{P}\right)$ & 1.1 & 0.1679 & 3.9 & 0.887 & 4.0 & - & - & - & - & 9.0 \\
\hline${ }^{17} \mathrm{Cl}\left({ }^{2} \mathrm{P}\right)$ & 1.1 & 0.1539 & 3.9 & 0.805 & 4.0 & - & - & - & - & 9.0 \\
\hline${ }^{18} \operatorname{Ar}\left({ }^{1} S\right)$ & 1.1 & 0.1439 & 3.9 & 0.739 & 4.0 & - & - & - & - & 9.0 \\
\hline${ }^{19} \mathrm{~K}\left({ }^{2} \mathrm{~S}\right)$ & 1.1 & 0.1349 & 3.9 & 0.672 & 4.0 & 2.97 & 1.0 & - & - & 10.0 \\
\hline${ }^{20} \mathrm{Ca}\left({ }^{1} \mathrm{~S}\right)$ & 1.1 & 0.1270 & 3.9 & 0.618 & 4.0 & 2.55 & 1.0 & - & - & 10.0 \\
\hline${ }^{21} \mathrm{Sc}\left({ }^{2} \mathrm{D}\right)$ & 1.1 & 0.1201 & 4.0 & 0.571 & 4.8 & 2.41 & 1.1 & - & - & 11.0 \\
\hline${ }^{22} \mathrm{Ti}\left({ }^{3} \mathrm{~F}\right)$ & 1.1 & 0.1138 & 4.0 & 0.529 & 5.8 & 2.36 & 1.1 & - & - & 12.0 \\
\hline${ }^{23} \mathrm{~V}\left({ }^{4} \mathrm{~F}\right)$ & 1.1 & 0.1083 & 4.0 & 0.493 & 6.7 & 2.32 & 1.1 & - & - & 13.0 \\
\hline${ }^{24} \mathrm{Cr}\left({ }^{7} \mathrm{~S}\right)$ & 1.1 & 0.1032 & 4.1 & 0.461 & 8.4 & 2.37 & 1.4 & - & - & 15.0 \\
\hline${ }^{25} \mathrm{Mn}\left({ }^{6} \mathrm{~S}\right)$ & 1.1 & 0.0986 & 4.1 & 0.433 & 8.7 & 1.26 & 1.1 & - & - & 15.0 \\
\hline${ }^{26} \mathrm{Fe}\left({ }^{5} \mathrm{D}\right)$ & 1.1 & 0.0944 & 4.1 & 0.412 & 8.6 & 2.15 & 1.2 & - & - & 15.0 \\
\hline${ }^{27} \mathrm{Co}\left({ }^{4} \mathrm{~F}\right)$ & 1.1 & 0.0904 & 4.2 & 0.393 & 8.6 & 2.04 & 1.1 & - & - & 15.0 \\
\hline${ }^{28} \mathrm{Ni}\left({ }^{3} \mathrm{~F}\right)$ & 1.1 & 0.0870 & 4.2 & 0.375 & 8.6 & 1.95 & 1.1 & - & - & 15.0 \\
\hline${ }^{29} \mathrm{Cu}\left({ }^{2} \mathrm{~S}\right)$ & 1.1 & 0.0837 & 4.2 & 0.361 & 8.5 & 1.97 & 1.2 & - & - & 15.0 \\
\hline${ }^{30} \mathrm{Zu}$ ('S) & 1.1 & 0.0807 & 4.2 & 0.345 & 8.6 & 1.81 & 1.1 & - & - & 15.0 \\
\hline${ }^{31} \mathrm{Ga}\left({ }^{2} \mathrm{P}\right)$ & 1.1 & 0.0778 & 4.2 & 0.329 & 8.6 & 1.57 & 2.1 & - & - & 16.0 \\
\hline${ }^{32} \mathrm{Ge}\left({ }^{3} \mathrm{P}\right)$ & 1.1 & 0.0751 & 4.2 & 0.314 & 8.6 & 1.37 & 3.1 & - & - & 17.0 \\
\hline${ }^{33}$ As $\left({ }^{4} S\right)$ & 1.1 & 0.0726 & 4.2 & 0.301 & 8.5 & 1.23 & 4.1 & - & - & 18.0 \\
\hline${ }^{34} \mathrm{Se}\left({ }^{3} \mathrm{P}\right)$ & 1.1 & 0.0702 & 4.2 & 0.288 & 8.6 & 1.15 & 4.1 & - & - & 18.0 \\
\hline${ }^{35} \mathrm{Br}\left({ }^{2} \mathrm{P}\right)$ & 1.1 & 0.0680 & 4.3 & 0.277 & 8.6 & 1.08 & 4.1 & - & - & 18.0 \\
\hline${ }^{36} \mathrm{Kr}\left({ }^{1} \mathrm{~S}\right)$ & 1.1 & 0.0659 & 4.3 & 0.267 & 8.6 & 1.02 & 4.1 & - & - & 18.0 \\
\hline${ }^{37} \mathrm{Rb}\left({ }^{2} \mathrm{~S}\right)$ & 1.1 & 0.0639 & 4.3 & 0.257 & 8.5 & 0.95 & 4.1 & 3.41 & 1.0 & 19.0 \\
\hline${ }^{38} \mathrm{Sr}\left({ }^{1} \mathrm{~S}\right)$ & 1.1 & 0.0621 & 4.3 & 0.248 & 8.5 & 0.89 & 4.1 & 2.95 & 1.0 & 19.0 \\
\hline${ }^{48} \mathrm{Cd}\left({ }^{1} \mathrm{~S}\right)$ & 1.1 & 0.0481 & 4.4 & 0.183 & 8.6 & 0.58 & 8.9 & 2.34 & 1.0 & 24.0 \\
\hline
\end{tabular}

${ }^{a} q^{K}$, electronic charge in the $K$ shell; $r^{K}$, radius of the $K$ shell; and $Q_{0}^{10}$, total electronic charge in sphere 10 a.u. radius.

between the two spins. The inspection of the Tables III and IV reveal that the deviations to the ideal occupation for the spin-dependent electron numbers are either only one half as large as for the total density or the larger deviation is given for the spin with the majority of the electrons (here designated to the up spin).

It is not clear yet whether the deviations of the shell electron numbers to the expected ones are due to the ELF formula or to the inaccuracy of the wave function used. The question is, if ELF computed from the exact electron density distribution and an exact $\tau$ could give the appropriate shell partitioning with the desired electron numbers.

\section{Conclusions}

Not only does ELF resolve the atomic shell structure for all atoms from $\mathrm{Li}$ to $\mathrm{Sr}$, it also gives 
TABLE IV

The ELF shell radii and electron numbers for the down spin computed from the atomic data of Clementi and Roetti [18]. ${ }^{\mathrm{a}}$

\begin{tabular}{|c|c|c|c|c|c|c|c|c|c|c|}
\hline Atom & $\begin{array}{l}q^{K} \\
(e)\end{array}$ & $\begin{array}{c}r^{k} \\
\text { (a.u.) }\end{array}$ & $\begin{array}{l}q^{L} \\
(e)\end{array}$ & $\begin{array}{c}r^{L} \\
\text { (a.u.) }\end{array}$ & $\begin{array}{l}q^{M} \\
(e)\end{array}$ & $\begin{array}{c}r^{M} \\
\text { (a.u.) }\end{array}$ & $\begin{array}{l}q^{N} \\
(e)\end{array}$ & $\begin{array}{c}r^{N} \\
\text { (a.u.) }\end{array}$ & $\begin{array}{l}q^{O} \\
(e)\end{array}$ & $\begin{array}{l}Q_{0}^{10} \\
(\mathrm{e})\end{array}$ \\
\hline${ }^{3} \mathrm{Li}\left({ }^{2} \mathrm{~S}\right)$ & 1.0 & - & - & - & - & - & -- & - & - & 1.0 \\
\hline${ }^{4} \mathrm{Be}\left({ }^{1} \mathrm{~S}\right)$ & 1.0 & 1.02 & 1.0 & - & - & - & - & - & - & 2.0 \\
\hline${ }^{5} \mathrm{~B}\left({ }^{2} P\right)$ & 1.0 & 0.78 & 1.0 & - & - & - & - & - & - & 2.0 \\
\hline${ }^{6} \mathrm{C}\left({ }^{3} \mathrm{P}\right)$ & 1.1 & 0.63 & 1.0 & - & - & - & - & -- & - & 2.0 \\
\hline${ }^{7} \mathrm{~N}\left({ }^{4} \mathrm{~S}\right)$ & 1.0 & 0.53 & 1.0 & - & - & - & - & - & - & 2.0 \\
\hline${ }^{8} \mathrm{O}\left({ }^{3} \mathrm{P}\right)$ & 1.0 & 0.42 & 2.0 & - & - & - & - & - & - & 3.0 \\
\hline${ }^{9} \mathrm{~F}\left({ }^{2} \mathrm{P}\right)$ & 1.1 & 0.35 & 2.9 & - & - & - & - & - & - & 4.0 \\
\hline${ }^{10} \mathrm{Ne}\left({ }^{1} \mathrm{~S}\right)$ & 1.1 & 0.30 & 3.9 & - & - & - & - & - & - & 5.0 \\
\hline${ }^{11} \mathrm{Na}\left({ }^{2} \mathrm{~S}\right)$ & 1.1 & 0.2640 & 3.9 & - & - & - & - & - & - & 5.0 \\
\hline${ }^{12} \mathrm{Mg}\left({ }^{1} \mathrm{~S}\right)$ & 1.1 & 0.2364 & 3.9 & 1.686 & 1.0 & - & - & - & - & 6.0 \\
\hline${ }^{13} \mathrm{Al}\left({ }^{2} \mathrm{P}\right)$ & 1.1 & 0.2140 & 3.9 & 1.427 & 1.0 & - & - & - & - & 6.0 \\
\hline${ }^{14} \mathrm{Si}\left({ }^{3} \mathrm{P}\right)$ & 1.1 & 0.1955 & 3.9 & 1.247 & 1.0 & - & - & - & - & 6.0 \\
\hline${ }^{15} \mathrm{P}\left({ }^{4} \mathrm{~S}\right)$ & 1.1 & 0.1800 & 3.9 & 1.112 & 1.0 & - & - & - & - & 6.0 \\
\hline${ }^{16} \mathrm{~S}\left({ }^{3} \mathrm{P}\right)$ & 1.1 & 1.1689 & 3.9 & 0.952 & 2.0 & - & - & - & - & 7.0 \\
\hline${ }^{17} \mathrm{Cl}\left({ }^{2} \mathrm{P}\right)$ & 1.1 & 0.1544 & 3.9 & 0.831 & 3.0 & - & - & - & - & 8.0 \\
\hline${ }^{18} \mathrm{Ar}\left({ }^{1} \mathrm{~S}\right)$ & 1.1 & 0.1439 & 3.9 & 0.739 & 4.0 & - & -- & - & -- & 9.0 \\
\hline${ }^{19} \mathrm{~K}\left({ }^{2} \mathrm{~S}\right)$ & 1.1 & 0.1350 & 3.9 & 0.673 & 4.0 & - & - & - & - & 9.0 \\
\hline${ }^{20} \mathrm{Ca}\left({ }^{1} \mathrm{~S}\right)$ & 1.1 & 0.1270 & 3.9 & 0.618 & 4.0 & 2.55 & 1.0 & - & - & 10.0 \\
\hline${ }^{21} \mathrm{Sc}\left({ }^{2} \mathrm{D}\right)$ & 1.1 & 0.1201 & 3.9 & 0.576 & 4.0 & 2.36 & 1.0 & - & - & 10.0 \\
\hline${ }^{22} \mathrm{Ti}\left({ }^{3} \mathrm{~F}\right)$ & 1.1 & 0.1138 & 3.9 & 0.541 & 4.0 & 2.22 & 1.0 & - & - & 10.0 \\
\hline${ }^{23} V\left({ }^{4} F\right)$ & 1.1 & 0.1083 & 3.9 & 0.510 & 4.0 & 2.10 & 1.0 & - & - & 10.0 \\
\hline${ }^{24} \mathrm{Cr}\left({ }^{7} \mathrm{~S}\right)$ & 1.1 & 0.1032 & 3.9 & 0.486 & 4.0 & - & - & - & - & 9.0 \\
\hline${ }^{25} \mathrm{Mn}\left({ }^{6} \mathrm{~S}\right)$ & 1.1 & 0.0985 & 3.9 & 0.459 & 4.0 & 1.90 & 1.0 & - & - & 10.0 \\
\hline${ }^{26} \mathrm{Fe}\left({ }^{5} \mathrm{D}\right)$ & 1.1 & 0.0944 & 4.0 & 0.431 & 4.9 & 1.87 & 1.0 & - & -- & 11.0 \\
\hline${ }^{27} \mathrm{Co}\left({ }^{4} \mathrm{~F}\right)$ & 1.1 & 0.0903 & 4.1 & 0.406 & 5.8 & 1.85 & 1.0 & - & - & 12.0 \\
\hline${ }^{28} \mathrm{Ni}\left({ }^{3} \mathrm{~F}\right)$ & 1.1 & 0.0870 & 4.1 & 0.383 & 6.7 & 1.83 & 1.1 & - & - & 13.0 \\
\hline${ }^{29} \mathrm{Cu}\left({ }^{2} \mathrm{~S}\right)$ & 1.1 & 0.0838 & 4.2 & 0.362 & 8.7 & $\ldots$ & - & - & - & 14.0 \\
\hline${ }^{30} \mathrm{Zn}\left({ }^{1} \mathrm{~S}\right)$ & 1.1 & 0.0807 & 4.2 & 0.345 & 8.6 & 1.81 & 1.1 & - & - & 15.0 \\
\hline${ }^{31} \mathrm{Ga}\left({ }^{2} \mathrm{P}\right)$ & 1.1 & 0.0778 & 4.2 & 0.329 & 8.6 & 1.64 & 1.1 & - & - & 15.0 \\
\hline${ }^{32} \mathrm{Ge}\left({ }^{3} \mathrm{P}\right)$ & 1.1 & 0.0751 & 4.2 & 0.315 & 8.7 & 1.51 & 1.0 & - & - & 15.0 \\
\hline${ }^{33}$ As $\left({ }^{4} S\right)$ & 1.1 & 0.0726 & 4.2 & 0.302 & 8.7 & 1.41 & 1.0 & - & - & 15.0 \\
\hline${ }^{34} \mathrm{Se}\left({ }^{3} \mathrm{P}\right)$ & 1.1 & 0.0702 & 4.2 & 0.289 & 8.6 & 1.24 & 2.0 & - & - & 16.0 \\
\hline${ }^{35} \mathrm{Br}\left({ }^{2} \mathrm{P}\right)$ & 1.1 & 0.0680 & 4.3 & 0.278 & 8.6 & 1.12 & 3.0 & - & - & 17.0 \\
\hline${ }^{36} \mathrm{Kr}\left({ }^{1} \mathrm{~S}\right)$ & 1.1 & 0.0659 & 4.3 & 0.267 & 8.6 & 1.02 & 4.1 & - & -- & 18.0 \\
\hline${ }^{37} \mathrm{Rb}\left({ }^{2} \mathrm{~S}\right)$ & 1.1 & 0.0639 & 4.3 & 0.257 & 8.5 & 0.95 & 4.1 & - & - & 18.0 \\
\hline${ }^{38} \mathrm{Sr}\left({ }^{1} \mathrm{~S}\right)$ & 1.1 & 0.0621 & 4.3 & 0.248 & 8.5 & 0.89 & 4.1 & 2.95 & 1.0 & 19.0 \\
\hline${ }^{48} \mathrm{Cd}\left({ }^{1} \mathrm{~S}\right)$ & 1.1 & 0.0481 & 4.4 & 0.183 & 8.6 & 0.58 & 8.9 & 2.34 & 1.0 & 24.0 \\
\hline
\end{tabular}

${ }^{\mathrm{a}} q^{K}$, electronic charge in the $K$ shell; $r^{K}$, radius of the $K$ shell; and $Q_{0}^{10}$, total electronic charge in sphere of 10 a.u. radius.

for shells, where the $3 d$-orbital contribution is not so high, electron numbers close to those given by the Periodic Table of the Elements. This is true for the total as well as the spin densities. Especially for the valence shell the number of electrons is remarkably close, mostly within an error of 0.1 electron, to the valence numbers known by chemists. This is a clear advantage against for instance $\nabla^{2} \rho$ which, as found by Schmider et al. [20], is not able to define the shells quantitatively.
It is possible, at least principally, to compute ELF from a given electron density (e.g., the experimental one). Then the atomic shell structure as determined from ELF is independent of any orbital representation (i.e., canonical or localized).

\section{ACKNOWLEDGMENTS}

The authors wish to thank Professor H. G. von Schnering for his steady interest, Professor V. H. 
Smith, Jr., for his valuable comments, and Professor B. Silvi for stimulating discussions.

\section{References}

1. J. T. Waber and D. T. Cromer, J. Chem. Phys. 42, 4116 (1965).

2. R. J. Boyd, Can. J. Phys. 56, 780 (1978).

3. A. M. Simas, R. P. Sagar, A. C. T. Ku, and V. H. Smith, Jr., Can. J. Chem. 66, 1923 (1988).

4. K. D. Sen, M. Slamet, and V. Sahni, Chem. Phys. Lett. 205, 313 (1993).

5. R. F. W. Bader, P. J. MacDougall, and C. D. H. Lau, J. Am. Chem. Soc. 106, 1594 (1984).

6. R. F. W. Bader and H. Essén, J. Chem. Phys. 80, 1943 (1984).

7. G. Hunter, Int. J. Quantum Chem. 29, 197 (1986).

8. R. P. Sagar, A. C. T. Ku, and V. H. Smith, Jr., Can. J. Chem. 66, 1005 (1988).

9. G. Sperber, Int. J. Quantum Chem. 5, 189 (1971).

10. W.-P. Wang and R. G. Parr, Phys. Rew. A 16, 891 (1977).
11. M. Kohout, A. Savin, and H. Preuss, J. Chem. Phys. 95, 1928 (1991).

12. K. D. Sen, T. V. Gayatri, R. Krishnaveni, M. Kakkar, H. Toufar, G. O. A. Janssens, B. G. Baekelant, R. A. Schoonheydt, and W. J. Mortier, Int. J. Quantum Chem., to appear.

13. R. P. Sagar, A. C. T. Ku, V. H. Smith, Jr., and A. M. Simas, J. Chem. Phys. 88, 4367 (1988).

14. Z. Shi and R. J. Boyd, J. Chem. Phys. 88, 4375 (1988).

15. A. D. Becke and K. E. Edgecombe, J. Chem. Phys. 92, 5397 (1990).

16. A. Savin, O. Jepsen, J. Flad, O. K. Andersen, H. Preuss, and H. G. von Schnering, Angew. Chem. 104, 186 (1992).

17. R. G. Parr and W. Yang, Density Functional Theory of Atoms and Molecules (Clarendon Press, Oxford, 1989).

18. E. Clementi and C. Roetti, At. Data Nucl. Data Tables 14, 218 (1974). (In the case of sulfur there is an error in the basis set for the neutral atom, so the basis set from the table for the isoelectronic series was used instead.)

19. H. Schmider, R. P. Sagar, and V. H. Smith, Jr., Can. J. Chem. Phys. 70, 506 (1992).

20. H. Schmider, R. P. Sagar, and V. H. Smith, Jr., J. Chem. Phys. 94, 8627 (1991). 